\title{
A PRESENÇA/AUSÊNCIA DA (NOVA) SOCIOLOGIA DA EDUCAÇÃO NAS DISSERTAÇÕES SOBRE O ENSINO DE SOCIOLOGIA NA EDUCAÇÃO BÁSICA
}

\author{
V. MELO* e V. R. FERREIRA \\ Universidade Federal de Alagoas (UFAL) \\ valcimelo@hotmail.com
}

Artigo submetido em setembro/2014 e aceito em dezembro/2014

DOI: $10.15628 /$ holos.2014.2373

\section{RESUMO}

Este trabalho busca responder se e de que modo as contribuições teóricas da Sociologia da Educação e da Nova Sociologia da Educação estão presentes nas dissertações de mestrado cujo tema desenvolve-se acerca do ensino de Sociologia em nível médio. Para tal, em um primeiro momento fazemos uma breve caracterização da Sociologia da Educação e da Nova Sociologia da Educação enquanto campos de conhecimento e investigação científica para, em seguida, analisarmos através das temáticas, autores $e$ enfoques presentes em 43 dissertações produzidas principalmente em Programas de Pós-Graduação em Educação ou Ciências Sociais/Sociologia a presença ou ausência do campo científico em tela. Por fim, verificase que somente cerca de um terço das produções analisadas apresenta alguma contribuição direta deste campo científico e que tal presença se caracteriza como um movimento crescente nos estudos desenvolvidos a partir do ano de 2006 - e com maior ênfase no Sul do País que concentra mais da metade das dissertações com este perfil.

PALAVRAS-CHAVE: Sociologia da Educação, Nova Sociologia da Educação, Ensino de Sociologia.

\section{THE PRESENCE/ABSENCE OF THE (NEW) SOCIOLOGY OF EDUCATION IN MASTER'S THESES ABOUT TEACHING OF SOCIOLOGY IN BASIC EDUCATION}

\begin{abstract}
This paper seeks to answer whether and how the theoretical contributions of the Sociology of Education and the New Sociology of Education are present in master's theses whose theme is developed about teaching of sociology at medium level. For this, at first we briefly characterize the Sociology of Education and the New Sociology of Education as a field of knowledge and scientific research for, then we look through the topics, authors and approaches present in 43 dissertations produced mainly in Programs
\end{abstract}

Postgraduaten in Education or Social Science/Sociology the presence or absence of the scientific field in screen. Finally, it follows that only about a third of the productions analyzed exhibit some direct contribution of this scientific field and that such presence is characterized as a growing movement in studies performed from the year 2006 - and with greater emphasis on South Country what home to more than half of the dissertations with this profile.

KEYWORDS: Sociology of Education, New Sociology of Education, Teaching of Sociology. 


\section{INTRODUÇÃO}

É sabido que a Sociologia da Educação (SE) enquanto campo de conhecimento científico se instituiu a partir dos anos 1950 em um momento histórico dominado por desigualdades sociais fortalecidas no pós Segunda Guerra Mundial. Esse cenário foi determinante para que surgissem estudos críticos sobre as desigualdades de oportunidades no processo dito de democratização do saber escolar, no bojo do qual estão as chamadas teorias da reprodução (NOGUEIRA, 1990). E para além desta perspectiva teórica, no contexto da década de 1970 emergiu a Nova Sociologia da Educação (NSE) com seu enfoque no currículo compreendido como aparelho ideológico de dominação, de disputa por poder e de contestação (SILVA, 2000).

Atualmente, as duas áreas de conhecimento que originaram esse novo campo científico (a Sociologia e a Educação) não apenas fornecem elementos analíticos para o mesmo, como também, se utilizam das contribuições da SE e da NSE em suas pesquisas. É o caso, por exemplo, do que vem acontecendo no Brasil acerca do ensino de Sociologia cuja produção se dá equilibradamente tanto nos departamentos de Educação como de Ciências Sociais/Sociologia.

Neste sentido, procuramos elucidar no presente trabalho de que forma os estudos acadêmicos, mais especificamente, as dissertações de mestrado que envolvem a temática ensino de Sociologia em nível médio fazem uso (se é que isso acontece) das contribuições teóricas da SE e da NSE. Para tal, fracionamos o trabalho em duas grandes etapas: na primeira, procuramos apresentar os principais contornos teóricos que delimitam o campo da Sociologia da Educação e da Nova Sociologia da Educação. Já em um segundo momento, analisamos 43 dissertações de mestrado defendidas entre os anos 2000 e 2014 cujo objeto foi o ensino de Sociologia no Ensino Médio, buscando responder se elas se utilizam (ou não) das contribuições do referido campo de conhecimento científico.

\section{A EDUCAÇÃO COMO OBJETO DE ESTUDO DA SOCIOLOGIA E A CONSTITUIÇÃO DA SE E DA NSE COMO CAMPOS DE INVESTIGAÇÃO CIENTÍFICA}

A relação entre educação e sociedade é objeto de reflexão das ciências humanas e sociais desde longa data, sendo Émile Durkheim, no caso específico do pensamento sociológico, o mais direto representante desta problemática entre os clássicos da Sociologia ${ }^{1}$, o qual é, inclusive, considerado precursor do campo científico que mais tarde seria denominado Sociologia da Educação (VAN HAECHT, 2008; FILLOUX, 2010).

As formulações educacionais deste autor, como desdobramento e aplicação de sua teoria sociológica funcionalista ${ }^{2}$, concebem a educação como um fato social responsável pela

\footnotetext{
${ }^{1}$ Com isso não queremos dizer que a problemática aqui referida não esteja também presente nos escritos de Marx e de Weber, mas apenas creditar a Durkheim o reconhecimento pela dedicação específica à questão tanto no exercício da docência, como em obras escritas na primeira e início da segunda década do século XX e postumamente publicadas como Educação e Sociologia (1922), A educação moral (1925) e A evolução pedagógica na França (1938) (DIAS, 1990).

${ }^{2}$ Corrente teórico-metodológica que concebe a sociedade como um organismo biológico constituído de subsistemas cuja função é manter o adequado funcionamento (equilíbrio) do todo social (SILVA, 1992).
}

HOLOS, Ano 30, Vol. 6 
"socialização metódica das novas gerações" (DURKHEIM, 2010, p. 49). Este processo, por sua vez, tem como sujeito as gerações adultas e como finalidade a formação em cada individuo do ser social mediante a internalização dos valores, técnicas, conhecimentos e normas necessários à adaptação, conservação e enriquecimento harmônico do meio social existente.

Intrinsecamente vinculada à divisão funcional do trabalho, a educação apresenta-se, em Durkheim, com caráter duplo, a saber: deve ao mesmo tempo inculcar nos indivíduos indistintamente elementos comuns a todos os membros da sociedade e desenvolver nos mesmos a especialização requerida pela divisão do trabalho social (DURKHEIM, 2010, p. 45-48).

No entanto, como observa Petitat (1994, p. 14), na medida em que para Durkheim "[...] a sociedade se apresenta como uma entidade que transcende as divisões sociais e que se impõe do exterior para dentro dos indivíduos", sua problemática centra-se demasiadamente no âmbito do consenso social, deixando de considerar o papel do conflito e da assimetria nas relações de forças em disputa no tocante à seleção dos valores a serem socialmente transmitidos pela educação.

É, pois, este o principal aspecto da Sociologia da Educação durkheimiana que parece sofrer uma guinada analítica na década de 1960 com os estudos "conflitualistas" (PETITAT, 1994). Ou seja, como observa Van Haecht (2008), apesar de Durkheim reconhecer a possibilidade objetiva de uma ciência da educação ao distinguir a atividade científica (teoria) da atividade artística (prática) e situar a pedagogia em uma posição intermediária (teoria prática), não serão os durkheimianos que desenvolverão tal perspectiva, e sim, os estudos do pós-guerra que se realizam ao avesso do funcionalismo e que a autora denomina-os de "sociologia "crítica" da educação.

Estes estudos, oriundos de variados campos do conhecimento (economia: Samuel Bowles e Herbert Gintis; filosofia: Christian Baudelot e Roger Establet, e Louis Althusser; sociologia: Pierre Bourdieu e Jean-Claude Passeron), apesar de suas especificidades teórico-metodológicas, buscam enfatizar a tese a partir da qual a escola não pode ser compreendida acima dos interesses e relações sociais de classe.

Situados no contexto eufórico e movediço do pós Segunda Guerra Mundial ${ }^{3}$, tais estudos apresentam-se como resposta teórica às esperanças ilusórias da época já estatisticamente problematizadas pelos estudos demográficos acerca das desigualdades educacionais e da relação entre escolarização, desenvolvimento econômico e mobilidade social (NOGUEIRA, 1990; FORQUIN, 1995; VAN HAECHT, 2008). De maneira geral, estas teorias tratam de demonstrar de modo negativo o caráter reprodutivista da educação escolar, denunciando-a como mecanismo de dominação de classe, inculcação ideológica, legitimação e perpetuação das desigualdades sociais.

\footnotetext{
${ }^{3}$ Neste período, sob a égide da Guerra Fria, desenvolveu-se o que ficou conhecido como Estado de bem-estar social em alusão às mudanças sociais (crescimento demográfico, modernização tecnológica, qualificação da mão-deobra...), políticas (ampliação dos direitos sociais à educação, trabalho, saúde, previdência, habitação...) e culturais (elevação do nível educacional...) propiciadas e requeridas pelo extraordinário crescimento econômico (BEHRING; BOSCHETTI, 2011). No entanto, apesar de num primeiro momento chegar a vender a ilusão de um "capitalismo de rosto humano" mediante o suposto enfrentamento das desigualdades sociais por meio da tríade educação emprego - mobilidade social, o "entusiasmo desenvolvimentista e produtivista" (NOGUEIRA, 1990) do pós-guerra logo mostrou seus limites, como enunciam os levantamentos estatísticos da década de 1960 e a "sociologia das desigualdades de acesso à educação" (FORQUIN, 1995) neles alicerçadas.
} 
Batizados no meio acadêmico como paradigma da reprodução, estes estudos não apenas sofreram (e sofrem) as mais variadas interpretações, críticas e sínteses ${ }^{4}$, como também, se tornaram percurso incontornável nas pesquisas sociológicas que tomam a educação como objeto de análise - seja para confirmar ou refutar, parcial ou totalmente, suas teses, seja para aperfeiçoar suas descobertas.

É, pois, neste sentido de aperfeiçoamento do paradigma da reprodução que surgem nos anos 1970 os estudos vinculados a Nova Sociologia da Educação (NSE). Isto é, se em um primeiro momento a Sociologia enquanto instrumento de investigação social no campo da educação se apresenta a partir de uma perspectiva estrutural, procurando elucidar as desigualdades sociais (em todos os níveis) a partir da relação entre indivíduo, estrutura social e educação, a NSE aparece como um movimento de reconceituação, como nos afirma Tomaz Tadeu da Silva (2000), a fim de compreender os processos no interior da instituição escolar (a famosa "caixa preta").

A Sociologia do Currículo, como costuma ser chamada a NSE, está também amparada numa perspectiva crítica sobre o referido tema, mas segue outras tendências teóricas para além do funcionalismo e do marxismo característicos dos estudos da SE, desenvolvendo-se a partir do interacionismo simbólico, da fenomenologia e etnometodologia e do neomarxismo (SILVA, 2000).

Notamos, também, além dessas tendências, que através de sua proposta de compreensão do comportamento humano Max Weber contribui, em certa medida, para compor esse quadro de tendências influenciadoras. Ou seja, através de sua Sociologia compreensiva na qual ganha centralidade reflexões acerca do indivíduo e de sua subjetividade, de sua consciência dotada de valores, sentido, representações que orientam suas ações, este autor parece-nos ganhar importância no terreno da NSE, ao influenciar as tendências teóricas citadas acima.

Para Forquin (1993), o interacionismo simbólico, a etnometodologia e a fenomenologia oferecem instrumentos de interpretação dos processos escolares a partir da comunicação entre os atores sociais, produzindo, então, uma nova forma de se construir o conhecimento. Isto é, para o autor, as novas configurações relacionais entre os atores sociais apoiadas em diferentes subculturas produzem, a partir dos processos escolares, uma intersubjetividade.

Já a crítica neomarxista, como nos aponta Silva (2000, p.45) enfatiza o "[...] papel ideológico do currículo". Partindo desse pressuposto, Apple (1999) identifica as novas problemáticas que emergem a partir da relação entre educação, Estado e políticas neoliberais, sobretudo, como os grupos hegemônicos, utilizando-se de políticas neoliberais, transformam seu capital cultural em conhecimento oficial.

Devemos considerar, no entanto, que Apple (1992 apud MOREIRA; SILVA, 1994) concebe o campo do currículo como um espaço conflituoso que tem por um lado um grupo que produz ideologias e, por outro, um grupo que as combate. Isto é, para o autor, o currículo constitui um elemento de representação do capital cultural e de valores ideológicos de um determinado grupo. No entanto, existe um movimento que vai de encontro às ideologias dominantes em uma relação

\footnotetext{
${ }^{4}$ Pierre Bourdieu, autor que em parceria com Jean-Claude Passeron escreve $A$ reprodução, um dos mais importantes estudos do paradigma em tela, destaca em entrevista à professora Maria Andréa Loyola que sua reação é de surpresa diante dos mal-entendidos em torno da obra, visto que, para ele, o fato de acentuar que o sistema de ensino contribui para a conservação (reprodução) social não significa dizer que ele só faça isso ou, menos ainda, que esteja, enquanto cientista, defendendo a conservação da ordem vigente.
} 
dialética entre estrutura social e campo cultural. Sob essa perspectiva, o que se estabelece não é uma relação de dominação somente, mas de tensão, de conflitos contínuos por legitimação. Como afirma o autor:

O que não é abordado em grandes detalhes é um conjunto de preocupações que envolve o que foi chamado de tendências contraditórias, resistências e conflitos em torno dessas forças ideológicas. Ou seja, a reprodução cultural e econômica não é o único fenômeno que está ocorrendo em nossas instituições educacionais [...] Já não é raro encontrar pessoas que, individualmente ou em grupos organizados, estão atuando de forma que podem oferecer importantes bases para um trabalho "contra-hegemônico", também [...] O reconhecimento de tal trabalho "contra-hegemônico", contudo, significa que analisar o modo pelo qual operam os poderosos interesses conservadores, tanto ideológicos como materiais, é tarefa da maior importância, que nos permite compreender melhor tanto as condições de atuação da educação, como as possibilidades de alteração dessas condições (APPLE, 1992 apud MOREIRA; SILVA, 1994 p.57-58).

Seguindo essa tendência crítica do currículo, a gênese do campo da NSE foi efetivamente demarcada através da publicação do livro Knowledge and Control, de Michael Young, obra na qual o autor concentra artigos que versam sobre a discussão curricular.

Assim, para a NSE o currículo é visto como um instrumento materializado que representa um determinado tipo de cultura (SACRISTÁN, 1998), se configura em uma forma de dominação e controle social, visto que a estrutura de um currículo reflete o modo como se organiza o poder em determinada sociedade a partir da seleção, distribuição, transmissão e classificação dos saberes escolares.

Dito isto, apresentaremos aqui, as perspectivas teóricas que se fizeram e se fazem presentes até hoje nesse campo de conhecimento (a NSE).

Partindo dessa premissa, tomamos a perspectiva analítica de Basil Bernstein para estabelecer nossa discussão. Para o referido autor, o currículo está diretamente relacionado a um sistema de códigos, ou melhor, de mensagens. O fio condutor de sua análise se concentra num tipo de organização curricular denominado por ele de delimitações rigorosas e delimitações vagas. Para ele, as nuances estabelecidas na estruturação do saber vão refletir em um modelo escolar rígido ou brando, vão configurar, por sua vez, as relações de poder na relação pedagógica e seus sistemas de mensagens. A internalização dos códigos escolares, segundo Bernstein, contribui para a construção da identidade do indivíduo, sobretudo, em seu processo de socialização, delineando, ainda, a ordem social (BERNSTEIN, 1971 apud FORQUIN, 1993).

Seguindo uma perspectiva de saberes escolares diferente de Bernstein, Young (2000) entende que o currículo representa um saber socialmente organizado, de modo que o arranjo curricular se dá através dos seguintes pressupostos "[...] (i) estratificação alta e baixa, (ii) maiores e menores graus de especialização e (iii) relações isoladas e conectivas entre as áreas de saber" (YOUNG, 2000, p. 31).

Para este autor, a estratificação/hierarquização dos saberes está estritamente relacionada à valoração de determinadas áreas do saber por parte da sociedade. Ou seja, é conferido ao conhecimento um status social, alto ou baixo, que se relaciona diretamente com as concepções 
históricas de determinadas épocas, as quais sãos, da mesma forma, socialmente construído ${ }^{5}$. A esse respeito Young (2010, p 197, grifos do autor) afirma que

Ao defender que todo conhecimento é social (uma verdade irrefutável, se não concedermos autoridade à revelação divina), conduziu à oposição de que os currículos não eram mais do que um reflexo dos interesses dos detentores do poder; por outras palavras, a idéia de que, na educação, como em qualquer outro domínio, é o poder que conta, não o conhecimento.

Orientado por uma perspectiva semelhante à de Young (2000) para o qual as matérias escolares se constituem o alicerce do currículo, Goodson (2011, p.117), define currículo como

[...] uma série de documentos que cobrem variados assuntos e diversos níveis, junto com a formulação de tudo - "metas e objetivos", conjuntos e roteiros - que, por assim dizer, constitui as normas, regulamentos e princípios que orientam o que deve ser lecionado.

Partindo desse pressuposto, o referido autor, consubstancia sua discussão a partir de uma perspectiva historiográfica. Assim, ele afirma que a natureza mutável das disciplinas permite às mesmas passarem de um estado de marginalidade a um estado disciplinar com um rigor de conhecimento. Afirma, ainda, que o status conferido à disciplina produz, em certa medida, relações conflituosas entre elas.

Diante do exposto, percebe-se que pensar sob a ótica da NSE significa pensar, caracteristicamente, sobre, como coloca Forquin (1993, p. 83) "[...] os fatores culturais da educação", para compreender o espaço escolar enquanto um espaço de negociação e, sobretudo, de disputas, sociais e culturais distintas - que é ao mesmo tempo produto e produtor de subjetividades.

\section{O ENSINO DE SOCIOLOGIA NAS DISSERTAÇÕES DE MESTRADO E SUA RELAÇÃO COM A SE E A NSE}

Como demonstramos até aqui, se em um primeiro momento a educação torna-se "problema sociológico" a partir de uma análise focada nas relações estruturais, nos processos macrossociais, com a NSE a centralidade "[...] situa-se ao nível das pequenas unidades de análise [...], sem que com isso estudos de caráter mais globalizante [...] tenham deixado de existir, evidentemente" (NOGUEIRA, 1990, p. 9), ou que não sejam buscados os nexos entre os casos estudados e a totalidade social dos quais são constituintes.

Por outro lado, é preciso reconhecer, como já alertava Tomaz Tadeu da Silva em um escrito de 1990 que

\footnotetext{
${ }^{5}$ Esse status adquirido pelo conhecimento e a forma como ele configura-se a partir das mudanças históricas e sociais exprime com clareza a relação entre trabalho e educação. Isto é, se em um primeiro momento, a divisão entre os currículos acadêmico e profissionalizante se deu baseada na cisão trabalho mental versus trabalho manual, em um momento posterior, tal divisão tende a ser superada a fim de proporcionar, por meio das matérias escolares, certa articulação entre teoria e prática. Ou seja, como observa Young (2000), o currículo baseado no ensino de matérias possui esquemas de pensamento/conhecimento que fornecem instrumentos necessários à compreensão da natureza mutável do trabalho e a sua articulação com as mudanças nas demais esferas da vida social.
} 
[...] Embora boa parte dos estudos e pesquisas em educação reivindique a utilização de alguma perspectiva sociológica, poucos pesquisadores, sobretudo no Brasil, realmente se identificam como fazendo Sociologia da Educação [...] (SILVA, 1990, p. 3).

É, pois, orientados por esta ressalva acerca deste caráter "ao mesmo tempo tão onipresente e tão pouco assumido como tal" (SILVA, 1990, p. 3) característico dos estudos sobre educação que nesta segunda parte procuramos analisar dissertações de mestrado defendidas principalmente em programas de pós-graduação em Educação ou Ciências Sociais/Sociologia cujo objeto de análise foi o ensino de Sociologia em nível médio. O objetivo é buscar responder se e de que modo aparece neles a contribuição da SE ou da NSE enquanto campos de conhecimento científico.

Para realizar o presente estudo, analisamos 43 dissertações defendidas entre os anos de 2000 e 2014, das quais 30 estão disponíveis para download no formato Portable Document Format $(P D F)$ no site do Laboratório de Ensino de Sociologia Florestan Fernandes (LabES), da Faculdade de Educação da Universidade Federal do Rio de Janeiro (UFRJ), e 13 foram conseguidas diretamente com os autores via email ou através de busca na internet ${ }^{6}$. Utilizamos o recorte temporal 2000 a 2014 porque não conseguimos localizar as quatro dissertações que conforme Handfas e Maçaira (2014) foram apresentadas entre 1993 e 1999.

A análise consistiu na leitura do resumo, do sumário, da introdução e da conclusão de cada dissertação no intuito de identificar as temáticas abordadas, o referencial teórico orientador e a perspectiva analítica adotada por cada estudo - trabalho que foi complementado pelo levantamento de nomes dos principais autores da SE ou da NSE presentes nos escritos através da ferramenta localizar do software Adobe Reader. Os autores buscados foram: 1) Durkheim como expoente do paradigma funcionalista em educação; 2) Bourdieu, Passeron, Establet, Baudelot, Althusser, Bowles e Gintis como teóricos representantes do paradigma da reprodução e 3) Apple, Young, Bernstein, Giroux e Goodson como autores da Nova Sociologia Educação ou, mais especificamente, dos estudos sobre o currículo. A consulta consistiu em localizar não apenas o nome do autor, mas também em identificar o contexto e a perspectiva teórica no qual o mesmo estava sendo citado, visto que a contribuição teórica de alguns deles não se limita à SE ou NSE, como é o caso de Durkheim e Bourdieu (e, sobretudo, este último) que em muitos estudos são citados mais no campo da pesquisa e da sociologia geral.

À par dos limites da metodologia adotada para um conhecimento mais profundo de cada estudo, mas considerando-a suficiente para os propósitos do presente escrito, apresentamos a seguir, num primeiro momento, uma caracterização geral das dissertações analisadas para, em seguida, traçar uma análise acerca da sua perspectiva analítica.

\footnotetext{
${ }^{6}$ Para ter acesso as dissertações ainda não disponíveis no LabES foi fundamental o anexo "Lista de dissertações de mestrado e teses de doutorado sobre ensino de sociologia na educação básica defendidas entre 1993 e 2012 , por ordem crescente de ano de conclusão" (HANDFAS; MAÇAIRA, 2014).
} 


\subsection{As temáticas das dissertações: enfoques e tendências}

Após anos de lutas e debates a Sociologia e a Filosofia foram finalmente reintroduzidas como disciplinas obrigatórias no Ensino Médio. Esta conquista que se deu a partir da aprovação da Lei no 11.684, de 02 de junho de 2008, a qual alterou o artigo 36 da Lei de Diretrizes e Bases da Educação Nacional de 1996 (LDB 9.394, de 20 de dezembro de 1996) é o principal fator responsável pelo crescimento do ensino de Sociologia como objeto de estudo das pesquisas acadêmicas (HANDFAS, 2011).

Esta produção que gerou dezenas de dissertações de mestrado, artigos científicos e algumas teses de doutoramento, tem coberto diversos aspectos que envolvem o trabalho com a disciplina Sociologia. Aqui, analisaremos a produção de dissertações cujas temáticas predominantes encontram-se agrupadas no quadro abaixo:

QUADRO 1 - Temáticas abordadas pelas dissertações sobre ensino de Sociologia.

\begin{tabular}{|c|c|c|}
\hline TEMÁTICA & QUANTIDADE $^{7}$ & AUTORES \\
\hline $\begin{array}{l}\text { Institucionalização/histórico do ensino da } \\
\text { sociologia }\end{array}$ & 8 & $\begin{array}{c}\text { Meucci (2000); Guelfi (2001); Santos (2002); Romano } \\
\text { (2009); Florêncio (2011); Fireman (2012); Silva (2012); } \\
\text { Feijó (2012); }\end{array}$ \\
\hline $\begin{array}{c}\text { Sentidos/finalidade/expectativas nos } \\
\text { documentos oficiais e/ou produção } \\
\text { acadêmica }\end{array}$ & 5 & $\begin{array}{l}\text { Perez (2002); Souza (2008); Moraes (2009); Lima, A. } \\
\text { (2012); Moura (2012); }\end{array}$ \\
\hline Expectativas de estudantes e professores & 8 & $\begin{array}{l}\text { Santos (2002); Mota (2003); Rêses (2004); Caju (2005); } \\
\text { Eras (2006); Rosa (2009); Lima, F. (2012); Mascarenhas } \\
\text { (2012) }\end{array}$ \\
\hline Didática e prática pedagógica & 7 & $\begin{array}{l}\text { Oliveira (2007); Cunha (2009); Leopoldo (2009); Motta } \\
\text { (2012); Lima, A. (2012); Carvalho (2012); Prado (2013); }\end{array}$ \\
\hline Recursos didático-pedagógicos & 5 & $\begin{array}{l}\text { Alves (2001); Takagi (2007); Leopoldo (2009); Senna } \\
\text { (2012); Alves (2013); }\end{array}$ \\
\hline Currículo & 16 & $\begin{array}{l}\text { Sarandy (2004); Coan (2006); Rodrigues (2007); Takagi } \\
\text { (2007); Souza (2008); Almeida (2009); Perucchi (2009); } \\
\text { Soares (2009); Stempkowsk (2010); Santos (2011); } \\
\text { Ferreira (2011); Motta (2012); Lima, A. (2012); Feijó } \\
\text { (2012); Prado (2013); Caridá (2014); }\end{array}$ \\
\hline Formação de professores & 3 & Pavei (2008); Rosa (2009); Lennert (2009); \\
\hline Trabalho docente & 4 & $\begin{array}{l}\text { Eras (2006); Lennert (2009); Rosa (2009); Zanardi } \\
\text { (2009); }\end{array}$ \\
\hline
\end{tabular}

Fonte: Elaboração própria.

Conforme nos aponta o quadro acima, a maior parte dos estudos tem como preocupação central o currículo, seja este analisado a partir dos conteúdos abordados, do processo de recontextualização da ciência de referência e/ou das ideias e valores predominantes em documentos oficiais, livros didáticos ${ }^{8}$, programas escolares, etc.

\footnotetext{
${ }^{7}$ A quantidade aqui referenciada não expressa a divisão exata dos 43 escritos analisados, uma vez que, como é possível perceber, alguns autores são contabilizados mais de uma vez em função do seu trabalho não se limitar a apenas uma das temáticas destacadas.

${ }^{8}$ Não consideramos o livro didático como uma temática específica porque, a nosso ver, ele aparece nas dissertações mais como fonte de informação acerca do currículo (SARANDY, 2004; COAN, 2006; ALMEIDA, 2009; PERUCCHI, 2009) ou do histórico/finalidade do ensino da disciplina (MEUCCl, 2000) do que propriamente como um objeto de análise.
} 
Este dado é curioso e chama a atenção pelo fato de ser uma temática em crescimento (e talvez seja realmente este um dos principais motivos para tal) num contexto no qual não temos um currículo nacional e oficialmente posto para o ensino de Sociologia em nível médio.

Em segundo lugar aparece a temática das expectativas acerca do ensino de sociologia, seja esta considerada apenas no tocante aos estudos que a abordaram tomando como fonte o discurso de estudantes e professores, seja no tangente às análises que buscaram tal problemática nos documentos oficiais ou na produção bibliográfica.

Ainda de acordo com o quadro 1, percebe-se que a temática da historicização do processo de institucionalização da Sociologia como disciplina escolar continua sendo revisitada por alguns estudos - embora não de forma original como nas primeiras dissertações, e sim, mais a título de contextualização histórica.

Por fim, também percebe-se que após a aprovação da obrigatoriedade nacional a preocupação dos pesquisadores desloca-se, de modo ascendente, para questões estruturantes (currículo, formação de professores, condições de exercício do magistério) e pedagógicas (métodos, processos e recursos de ensino), confirmando o que destacam Handfas e Maçaira quando ao analisaram a questão em tela afirmam:

[...] as pesquisas estão muito mais voltadas para um olhar para a sala de aula - no sentido de compreender as formas de implementação da disciplina nos currículos, nos recursos didáticos e na prática pedagógica do professor de sociologia - do que para uma compreensão mais ampla dos processos didáticos, históricos e sociológicos que envolvem a presença da sociologia no contexto escolar. Nesse sentido, observamos a preponderância de estudos descritivos de práticas de professores, das experiências de ensino e do uso de recursos didáticos, a partir de metodologias como estudos de caso, entrevistas e questionários (HANDFAS; MAÇAIRA, 2014, p. 56).

\subsection{A SE e a NSE nos estudos sobre ensino de sociologia}

Conforme visto até aqui, o ensino de Sociologia na última etapa da Educação Básica tem se constituindo um campo de estudo científico em crescimento, sendo o currículo e a finalidade de tal ensino as temáticas mais recorrentes nas dissertações de mestrado analisadas.

Aqui, por sua vez, procuramos localizar nas mesmas dissertações a presença/ausência da SE/NSE como suporte teórico dos estudos em tela, principalmente após constatar os enfoques temáticos das produções sobre os quais o campo científico em discussão parece-nos ter muito a dizer.

Para tal, como já anunciamos anteriormente, buscamos localizar nas dissertações os principais autores ligados a SE/NSE e as ideias e conceitos a partir dos quais eles foram reivindicados em cada estudo.

Os autores da SE mais citados pelos estudos são Émile Durkheim e Pierre Bourdieu, sendo o primeiro citado diretamente em 21 (das 43) dissertações, e o segundo em 23. Já os autores da Nova Sociologia da Educação ou Sociologia do Currículo, apesar de estarem presentes nos estudos sobre ensino de Sociologia em nível médio de modo menos frequente que os primeiros (Giroux 
aparece em 02 dissertações; Young em 03; Bernstein e Goodson em 04 e Apple em 5), as dissertações que os referenciam se apropriam de maneira mais intensa de suas contribuições do que os estudos amparados nos autores da SE. Observa-se também que dos 08 trabalhos nos quais os teóricos da NSE aparecem, 05 foram defendidos entre 2011 e 2014 em universidades do Sul do País, sendo 03 deles na Universidade Estadual de Londrina (UEL) e sob a orientação da professora Dra. Ileizi Luciana Fiorelli Silva. Já entre os autores brasileiros, Paulo Freire é o mais citado, estando presente em 06 dissertações.

Ainda acerca dos teóricos da SE acima mencionados (Bourdieu e Durkheim), cabe observar que como são autores cuja produção teórica não está circunscrita ao campo de estudo em análise, o fato de estarem sendo citados em pesquisas que versam sobre o ensino de Sociologia não significa que se trate de produções à luz da Sociologia da Educação.

É, pois, o que se constata quando partimos para a análise do contexto no qual os referidos autores são citados ou referenciados. No caso de Durkheim, por exemplo, somente 13 dos 21 trabalhos que o citam fazem referência à sua teoria educacional - sem falar que a imensa maioria das referências ao autor se dá no sentido de caracterizar o que se denomina perspectiva funcionalista em educação ou em virtude de sua influência em um dos períodos da história da educação brasileira, e não, como suporte teórico a partir do qual se desenvolve o trabalho. Já no tocante a Bourdieu a situação é mais complexa ainda, visto tratar-se de um dos mais reconhecidos autores da Sociologia contemporânea. Isto é, o autor é mais citado nas dissertações em virtude da sua contribuição para a sociologia geral (15 dos 23 estudos) do que como sociólogo da educação.

Ainda sobre este aspecto, observa-se que dos 43 estudos analisados, apenas 2 se autodenominam como referenciados na Sociologia da Educação (LENNERT, 2009; CARVALHO, 2012). Entre os demais, apesar de apenas 10 deles não fazerem qualquer referência aos autores da SE/NSE, verifica-se que somente cerca de $1 / 3$ (um terço) das produções analisadas apresentam alguma contribuição direta deste campo científico e que tal presença se caracteriza de modo mais claro nos estudos desenvolvidos a partir do ano de 2006 - e com maior ênfase no Sul do País que concentra quase metade das dissertações com este perfil ${ }^{9}$.

O dado causa surpresa não pela qualidade política dos estudos, visto que predomina nos mesmos o que poderíamos chamar de perspectiva crítica em educação (SILVA, 1992), mas pela ausência do referido aporte teórico em produções que giram em torno de temáticas cuja contribuição deste campo científico é incontornável, como é o caso dos estudos que tratam do currículo ou da finalidade do ensino da disciplina nos quais a contribuição da SE/NSE ainda é parca - apesar de ser nas pesquisas que discorrem sobre a primeira temática que se observa uma maior contribuição teórica deste campo científico.

\section{CONSIDERAÇÕES FINAIS}

Neste trabalho, buscamos identificar se e de que forma as contribuições teóricas da Sociologia da Educação, bem como, da Nova Sociologia da Educação estão presentes nas

\footnotetext{
${ }^{9}$ No que se refere à relação origem departamental - contribuição da SE ou da NSE as dissertações analisadas não apresentam novidade, visto que entre os trabalhos nos quais se verificou a presença do campo científico em análise, metade são oriundos dos Programas de Educação e a outra parte dos de Ciências Sociais.
}

HOLOS, Ano 30, Vol. 6 
dissertações sobre o ensino de Sociologia na Educação Básica. Para tal, em um primeiro momento, procuramos delinear os contornos teóricos alusivos às respectivas áreas (que vão desde uma perspectiva estrutural, macrossocial, a uma concepção local e microssocial), para em seguida, verificarmos se e de que modo ambas as correntes teóricas estão assumidas nas produções acerca do ensino de Sociologia.

De modo geral, notamos a atualidade da tese de Tomaz Tadeu da Silva que no início dos anos 1990 já destacava a Sociologia da Educação com um campo "[...] ao mesmo tempo tão onipresente e tão pouco assumido como tal” (SILVA, 1990, p. 3). Isto é, apesar de verificarmos que a maioria absoluta dos estudos pauta-se, de algum modo, no que poderia ser considerada uma perspectiva crítica em educação (daí a onipresença de algo modo da SE ou da NSE), é patente a ausência do referido campo teórico como suporte analítico na maior parte das dissertações mapeadas. Isto, por sua vez, embora não seja demérito da produção em exame, visto que seria um tanto ingênuo supor que o referencial teórico em discussão é o único capaz de fornecer o melhor suporte analítico para o objeto em tela (ensino de Sociologia), caracteriza, a nosso ver, certo paradoxo tanto pelo fato de parte considerável dos trabalhos mapeados dedicar-se a temáticas cuja contribuição teórica deste campo científico não pode ser simplesmente ignorada (seja, inclusive, para refutar seus postulados), como também, por tratar-se de um objeto de estudo que uma vez situado entre as Ciências Sociais e a Educação precisaria articular melhor e de modo mais explícito a relação entre estas duas áreas - o que necessariamente passaria pela SE ou NSE como paradigmas representativos dos estudos educacionais à luz da teoria sociológica.

\section{REFERÊNCIAS BIBLIOGRÁFICAS}

1. ALMEIDA, Djair Lázaro de. Educação Moral e Cívica na Ditadura Militar: um estudo dos manuais didáticos. 2009. 182f. Dissertação (Mestrado em Educação) - Universidade Federal de São Carlos, São Paulo, 2009.

2. ALVES, Elaine Gonçalves. Interface pedagógica virtual para a prática docente de sociologia: o portal Centro de Referência Virtual do professor (CRV). 2013. [s.n]. Dissertação (Mestrado em Ciências Sociais) - Universidade Federal de Uberlândia, Uberlândia, 2013.

3. ALVES, Maria Adélia. Filmes na escola: uma abordagem sobre o uso de audiovisuais (vídeo, cinema e programas de TV) nas aulas de Sociologia do Ensino Médio. 2001. [s.n]. Dissertação (Mestrado em Educação) - Faculdade de Educação da Universidade Estadual de Campinas, Campinas, 2001.

4. APPLE, Michael W. Políticas culturais e educação. Portugal: Porto Editora, 1999.

5. BEHRING, Elaine Rosseti; BOSCHETTI, Ivanete. Política social: fundamentos e história. 9. ed. São Paulo: Cortez, 2011.

6. BOURDIEU, Pierre; PASSERON, Jean-Claude. A reprodução. Petrópolis, RJ: Vozes, 2008 (tradução: Reynaldo Bairão).

7. BRASIL. Lei no 9.394, de 20 de dezembro de 1996. Estabelece as diretrizes e bases da educação nacional. Diário Oficial da União, Brasília, 23 de dezembro de 1996.

8. L__ Lei n.. 11.648, de 2 de junho de 2008. Altera o art. 36 da lei n. 9 9.394, de 20 de dezembro de 1996, que estabelece as diretrizes e bases da educação nacional, para incluir a 
Filosofia e a Sociologia como disciplinas obrigatórias nos currículos do ensino médio. Diário Oficial da União, Brasília, 3 de junho de 2008.

9. CAJU, Andréia Vânia Ferreira. Análise da disciplina Sociologia na Educação Profissional: reflexões a partir de um estudo de caso. 2005. 129 f. Dissertação (Mestrado em Educação Agrícola) - Universidade Federal Rural do Rio de Janeiro, Seropédica - RJ, 2005.

10. CARIDÁ, Ana Carolina Bordini Brabo. Sociologia no ensino médio: diretrizes curriculares e trabalho docente. 2014. 145f. Dissertação (Mestrado em Sociologia Política) - Universidade Federal de Santa Catarina, Florianópolis, 2014.

11. CARVALHO, Tatiane Kelly Pinto de. Ensino de sociologia: elementos da prática docente no ensino médio. 2012. 185f. Dissertação (Mestrado em Educação) - Universidade do Estado de Minas Gerais, Belo Horizonte, 2012.

12. COAN, Marival. A Sociologia no ensino médio, o material didático e a categoria trabalho. 2006. [s.n]. Dissertação (Mestrado em Educação) - Centro de Educação da Universidade Federal de Santa Catarina, Florianópolis, 2006.

13. CUNHA, Patrícia. 0 ensino de Sociologia: uma experiência em sala de aula. 2009. [s.n]. Dissertação (Mestrado em Sociologia) - Departamento de Ciências Sociais da Universidade Federal do Ceará, Fortaleza, 2009.

14. DIAS, Fernando Correia. Durkheim e a Sociologia da Educação no Brasil. Em Aberto, Brasília, ano 9, n. 46, p. 33-48, abr. jun. 1990.

15. DURKHEIM, Émile. Educação e sociologia. In: FILLOUX, Jean-Claude. Émile Durkheim. Recife: Fundação Joaquim Nabuco, Editora Massangana, 2010. (tradução: Celso do Prado Ferraz de Carvalho, Miguel Henrique Russo - Coleção Educadores).

16. ERAS, Lígia Wilhelms. O trabalho docente e a discursividade da autopercepção dos professores de sociologia e filosofia no ensino médio em Toledo/PR. 2006. 277 f. Dissertação (Mestrado em Letras) - Universidade Estadual do Oeste do Paraná, Paraná, 2006.

17. FEIJÓ, Fernanda. A sociologia contemporânea na sala de aula: (re)pensando algumas perspectivas para o ensino das ciências sociais no ensino médio. 2012. 123f. Dissertação (Mestrado em Sociologia) - Universidade Estadual Paulista "Júlio de Mesquita Filho", Araraquara (SP), 2012.

18. FERREIRA, Eduardo Carvalho. Sobre a noção de conhecimento escolar de Sociologia. 2011. [s.n]. Dissertação (Mestrado em Ciências Sociais) - Universidade Estadual de Londrina, Londrina, PR, 2011.

19. FILLOUX, Jean-Claude. Émile Durkheim. Recife: Fundação Joaquim Nabuco; Editora Massangana, 2010. (tradução: Celso do Prado Ferraz de Carvalho, Miguel Henrique Russo Coleção Educadores).

20. FIREMAN, Eleclézia de Oliveira. Uma abordagem sociológica do relato da obrigatoriedade do ensino de sociologia no Ensino Médio. 2012. 105f. Dissertação (Mestrado em Sociologia) Universidade Federal de Alagoas, Maceió, 2012.

21. FLORÊNCIO, Maria Amélia de Lemos. $O$ ensino da sociologia no nível médio e as contradições institucionais de sua obrigatoriedade. 2011. Dissertação (Mestrado em Sociologia) Universidade Federal de Alagoas, Maceió, 2011. 
22. FORQUIN, Jean-Claude. Escola e cultura: as bases sociais e epistemológicas do conhecimento escolar. Porto Alegre: Artes Médicas, 1993.

23. Sociologia das desigualdades de acesso à educação: principais orientações, principais resultados desde 1965. In: FORQUIN, Jean Claude (org.) Sociologia da educação: dez anos de pesquisa. Petrópolis: Vozes, 1995 (tradução: Guilherme João de Freitas Teixeira).

24. GOODSON, Ivor F. Currículo: teoria e história. Petrópolis, RJ: Vozes, 2011.

25. As políticas de currículo e de escolarização: abordagens históricas. Petrópolis, RJ: Vozes, 2008.

26. GUELFI, Wanirley Pedroso. A Sociologia como disciplina escolar no Ensino Secundário brasileiro (1925-1942). 2001. 194f. Dissertação (Mestrado em Educação) - Universidade Federal do Paraná, 2001.

27. HANDFAS, Anita. O estado da arte do ensino de Sociologia na Educação Básica: um levantamento preliminar da produção acadêmica. Inter-legere, Natal, RN, n. 9, p. 386-400, jul./dez. 2011. Disponível em: http://periodicos.ufrn.br/interlegere/article/view/4403. Acesso em: 22 set. 2013.

28. __ _ _ MAÇAÍRA, Julia Polessa. O estado da arte da produção científica sobre o ensino de sociologia na educação básica. BIB, São Paulo, no 74, pp. 43-59, jul. 2014.

29. LENNERT, Ana Lucia. Professores de Sociologia: relações e condições de trabalho. 2009. [s.n]. Dissertação (Mestrado em Educação) - Faculdade de Educação da Universidade Estadual de Campinas, Campinas, 2009.

30. LEODORO, Silvana Aparecida Pires. A disciplina Sociologia no Ensino Médio: perspectivas de mediação pedagógica e tecnológica. Um diálogo possível. 2009. 252f. Dissertação (Mestrado em Educação) - Universidade de São Paulo, São Paulo, 2009.

31. LIMA, Alexandre Jerônimo Correia. Teorias e métodos em pesquisa sobre ensino de sociologia. 2012. 298f. Dissertação (Mestrado em Ciências Sociais) - Universidade Estadual de Londrina, 2012.

32. LIMA, Fabiana Conceição Ferreira de. A sociologia no ensino médio e sua articulação com as concepções de cidadania dos professores. 2012. 130f. Dissertação (Mestrado em Sociologia) Universidade Federal de Pernambuco, Recife, 2012.

33. MASCARENHAS, Alexandra Garcia. As representações dos professores e estudantes sobre a sociologia no ensino médio: investigando as comunidades virtuais do Orkut. 2012. $129 f$. Dissertação (Mestrado em Educação) - Universidade Federal de Pelotas, Pelotas (RS), 2012.

34. $\mathrm{MEUCCl}$, Simone. A institucionalização da sociologia no Brasil: os primeiros manuais e cursos. 2000. [s.n]. Dissertação (Mestrado em Sociologia) - Universidade Estadual de Campinas, Campinas (SP), 2000.

35. MORAES, Luiz Fernando Nunes. Da Sociologia cidadã à cidadania sociológica: as tensões e disputas na construção dos significados de cidadania e do ensino de sociologia, 2009. $240 \mathrm{f}$. Dissertação (Mestrado em Sociologia) - Universidade Federal do Paraná, Paraná, 2009.

36. MOREIRA, Antonio Flávio. SILVA, Tomaz Tadeu da (orgs.). MOREIRA, Antonio Flávio (orgs.). Currículo, cultura e sociedade. 2. ed. São Paulo: Cortez, 1994. 
37. MOTA, Kelly Cristine Côrrea da Silva. Os lugares da Sociologia na educação escolar de jovens do ensino médio: formação ou exclusão da cidadania e da crítica? 2003. 222 f. Dissertação (Mestrado em Educação) - Universidade do Vale do Rio dos Sinos, São Leopoldo, RS, 2003.

38. MOTTA, Átila Rodolfo Ramalho. Que sociologia é essa? Análise da recontextualização pedagógica do conhecimento sociológico. 2012. 177f. Dissertação (Mestrado em Ciências Sociais) - Universidade Estadual de Londrina, Londrina (PR), 2012.

39. MOURA, Neide de Lima. O papel da sociologia na formação do jovem: perspectivas dos estudantes. 2012. 147f. Dissertação (Mestrado em Educação) - Universidade Nove de Julho, São Paulo, 2012.

40. NOGUEIRA, Maria Alice. A sociologia da educação do final dos anos 60 / início dos anos 70: o nascimento do paradigma da reprodução. Em Aberto, Brasília, ano 9, n. 46, p. 49-58, abr. jun. 1990.

41. OLIVEIRA, Dalta Motta de. A prática pedagógica dos professores de Sociologia: entre a teoria e a prática. 2007. [s.n]. Dissertação (Mestrado em Educação) - Universidade Estácio de Sá, Rio de Janeiro, 2007.

42. PAVEI, Katiuci. Reflexões sobre o ensino e a formação de professores de Sociologia. 2008. [s.n]. Dissertação (Mestrado em Educação) - Faculdade de Educação da Universidade Federal do Rio Grande do Sul, Porto Alegre, 2008.

43. PEREZ, Cilmara Ferrari. A formação sociológica de normalistas nas décadas de 20 e 30. 2002. [s.n]. Dissertação (Mestrado em Educação) - Universidade Estadual de Campinas, Campinas (SP), 2002.

44. PERUCCHI, Luciane. Saberes sociológicos nas escolas de nível médio sob a ditadura militar: os livros didáticos de OSPB. 2009. [s.n]. Dissertação (Mestrado em Educação) - Universidade Federal de Santa Catarina, Florianópolis, 2009.

45. PETITAT, André. Produção da escola, produção da sociedade: análise sócio-histórica de alguns momentos decisivos da evolução escolar no ocidente. Porto Alegre: Artes Médicas, 1994 (tradução: Eunice Gruman).

46. PRADO, Gregório Antonio Fominski do. Quando o ensino desafia a ciência: algumas questões presentes nos processos de ensino-aprendizagem da sociologia. 2013. 226f. Dissertação (Mestrado em Ciências Sociais) - Universidade Estadual de Londrina, Londrina (PR), 2013.

47. RÊSES, Orlando da Silva. E com a palavra: os alunos - estudo das representações sociais dos alunos da rede pública do Distrito Federal sobre a Sociologia no ensino médio. 2004. 134f. Dissertação (Mestrado em Sociologia) - Instituto de Ciências Sociais da Universidade de Brasília, Brasília, 2004.

48. RODRIGUES, Shirlei. Cidadania e espaço público a partir da escola: resgate, recriação ou abandono? 2007. [s.n]. Dissertação (Mestrado em Sociologia) Instituto de Ciências Sociais da Universidade de Brasília, Brasília, 2007.

49. ROMANO, Fábio Geraldo. A luta em defesa da sociologia no Ensino Médio (1996-2007): um estudo sobre a invenção das tradições. 2009. 155f. Dissertação (Mestrado em Educação Escolar) - Universidade Estadual Paulista, Araraquara (SP), 2009.

50. ROSA, Maristela. $\mathbf{O}$ trabalho docente com a disciplina de Sociologia: algumas reflexões sobre 
o ser professor no ensino médio da rede pública de Santa Catarina. 2009. [s.n]. Dissertação (Mestrado em Educação) - Faculdade de Educação da Universidade Federal de Santa Catarina, Florianópolis, 2009.

51. SACRISTÁN, José Gimeno. O currículo: uma reflexão sobre a prática. 3. ed. Porto Alegre: ArtMed, 1998 (tradução de Ernani F. da F. Rosa).

52. SANTOS, Mário Bispo dos. A Sociologia no ensino médio: o que pensam os professores da rede pública do Distrito Federal. 2002. 170 f. Dissertação (Mestrado em Sociologia) - Instituto de Ciências Sociais da Universidade de Brasília, Brasília, 2002.

53. SANTOS, Renata Oliveira dos. A implementação da sociologia nas instituições privadas paranaenses: um estudo sociológico. 2011. [s.n]. Dissertação (Mestrado em Ciências Sociais) Universidade Estadual de Maringá, Maringá (PR), 2011.

54. SARANDY, Flávio Marcos Silva. A Sociologia volta à escola: um estudo dos manuais de Sociologia para o ensino médio no Brasil. 2004. 142 f. Dissertação (Mestrado em Sociologia e Antropologia) - Universidade Federal do Rio de Janeiro, Rio de Janeiro, 2004.

55. SENNA, Alecrides Jahne Raquel Castelo Branco de. Diálogos com o homem imaginário: pensando o uso de imagens no ensino de sociologia. 2012. 91f. Dissertação (Mestrado em Ciências Sociais) - Universidade Federal do Rio Grande do Norte, Natal, 2012.

56. SILVA, Kátia Karine Duarte da. Políticas educacionais para a inserção da sociologia no ensino médio em Mato Grosso do Sul (1999-2010). 2012. 169f. Dissertação (Mestrado em Educação) - Universidade Federal de Mato Grosso do Sul, Campo Grande, 2012.

57. SILVA, Tomaz Tadeu da. A sociologia da educação entre o funcionalismo e pós-modernismo: os temas e os problemas de uma tradição. Em Aberto, Brasília, ano 9, n. 46, p. 3-12, abr. jun. 1990.

58. _. . . 0 que produz e o que reproduz em educação: ensaios de sociologia da educação. Porto Alegre: Artes Médicas, 1992.

59. __ Teorias do currículo: uma introdução crítica. Portugal: Porto Editora, 2000.

60. SOARES, Jefferson da Costa. O ensino de Sociologia no Colégio Pedro II (1925-1941). 2009. 139f. Dissertação (Mestrado em Educação) - Universidade Federal do Rio de Janeiro, Rio de Janeiro, 2009.

61. SOUZA, Shelley. A defesa da disciplina Sociologia nas políticas para o ensino médio de 1996 a 2007. 2008. [s.n]. Dissertação (Mestrado em Educação) - Faculdade de Educação da Universidade Federal do Rio de Janeiro, Rio de Janeiro, 2008.

62. STEMPKOWSKI, Ivete Fatima. A influência social na construção do conhecimento: a formação dos currículos de Sociologia no ensino médio. 2010. [s.n]. Dissertação (Mestrado em Ciências Sociais) - Faculdade de Filosofia e Ciências Humanas da Pontifícia Universidade Católica do Rio Grande do Sul, Porto Alegre, 2010.

63. TAKAGI, Cassiana Tieme Tedesco. Ensinar sociologia: análise dos recursos de ensino na escola média. 2007. [s.n]. Dissertação (Mestrado em Educação) - Faculdade de Educação, Universidade de São Paulo, São Paulo, 2007.

64. VAN HAECHT, Anne. A emergência da sociologia "crítica" da educação. In: Sociologia 
da educação: a escola posta à prova. 3. ed. Porto Alegre: Artmed, 2008 (tradução: Sandra Loguercio).

65. YOUNG, Michael F. D. Conhecimento e currículo: do socioconstrutivismo ao realismo social na Sociologia da Educação. Portugal: Porto Editora, 2010 (tradução de Jorge Ávila de Lima).

66. Michael F. D. O currículo do futuro: da "Nova Sociologia da Educação" a uma teoria crítica do aprendizado. Campinas, SP: Papirus, 2000.

67. ZANARDI, Gabriel. A re-introdução da Sociologia nas escolas públicas: caminhos e ciladas para o trabalho docente. 2009. [s.n]. Dissertação (Mestrado em Educação) - Faculdade de Ciências e Letras da Universidade Estadual Paulista Julio de Mesquita Filho, Araraquara, SP, 2009. 